\title{
ORGANIC POLLUTANTS IN THE GROUNDWATERS USED FOR IRRIGATION PURPOSE WITHIN A COAL-BEARING BASIN OF NORTHERN GREECE
}

\author{
Iordanidis A. ${ }^{1}$, Schwarzbauer J. ${ }^{2}$ and Gudulas K. ${ }^{1}$ \\ ${ }^{I}$ Department of Geotechnology and Environmental Engineering, Technological Educational \\ Institute (TEI) of Western Macedonia, Kila, 50100 Kozani, Greece, aiordanidis@yahoo.co.uk, \\ kgudulas@teikoz.gr \\ ${ }^{2}$ Institute of Geology and Geochemistry of Petroleum and Coal, RWTH Aachen University, \\ Lochnerstrasse 4-20, 52056 Aachen, Germany, jan.schwarzbauer@emr.rwth-aachen.de
}

\begin{abstract}
The aim of this study is to identify potential toxic or environmentally relevant organic compounds in the aquifers of the Amynteo hydrogeological basin and to investigate a possible link of the identified organic contaminants with the Pliocene Amynteo lignites. For these purposes ten groundwater samples were collected from this area. A sequential liquid-liquid extraction procedure was applied to approximately $1000 \mathrm{~mL}$ aliquots of the groundwater samples using dichloromethane as extractant. All extracts were analysed by Gas Chromatography (GC) and Gas-Chromatography-Mass Spectrometry $(G C-M S)$ by means of a non-target screening approach. The results of the GC-MS analyses of the extracts are presented and discussed in this work. The identified organic compounds with a potential environmental relevance are: 2, 2, 4-trimethyl-1, 3pentanediol diisobutyrate (TXIB), triacetine, isopropyl palminate, isopropyl myristate, tributyl-, triethyl- and trioctylphosphates, $N, N$-dibutyl formamide, methyl dihydrojasmonate, nonylphenols and bumetrizole. However, all these organic micropollutants can derive either by anthropogenic emissions (plasticizers, industrial pollutants, pesticides etc.) or by contaminations from the pump and the borehole structure itself. Noteworthy, coal derived organic molecules (such as anthracene, fluorene, pyrene, phenanthrene etc.) have not been detected. Hence, an influence of coal deposits to the groundwater quality is considered negligible.
\end{abstract}

Keywords: organics, liquid-liquid extraction, GC-MS, Amynteo.

\section{Пєрí $\eta \psi \eta$}

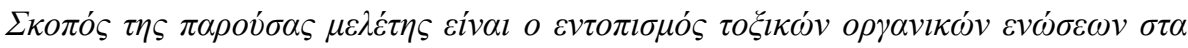

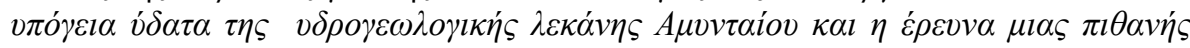

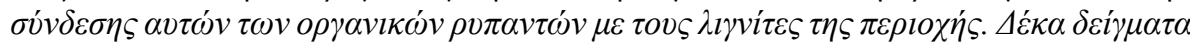

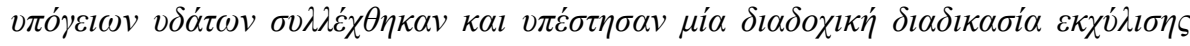

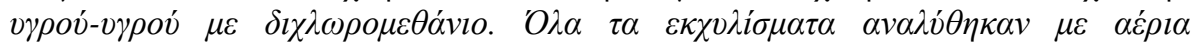

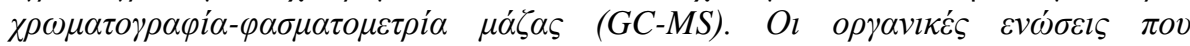

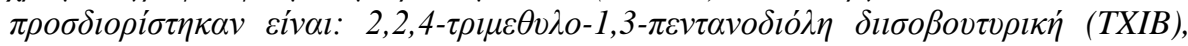

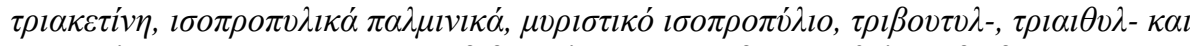

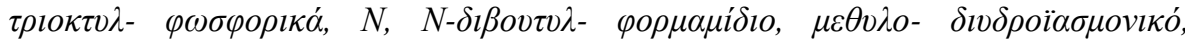

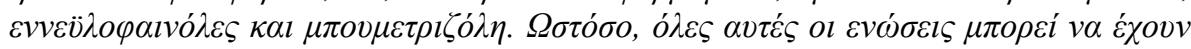

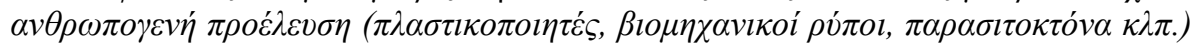




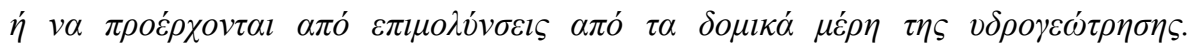
A

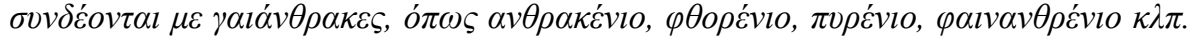

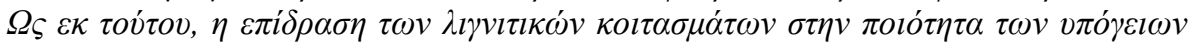

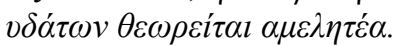

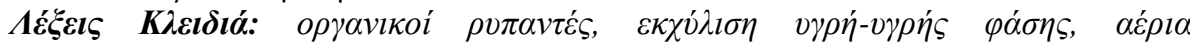
$\chi \rho \omega \mu \alpha \tau о \gamma \rho \alpha \varphi i ́ \alpha$.

\section{Introduction}

Groundwater use represents $42 \%$ of the total demanded hydraulic resources in Greece including $36 \%$ in agriculture, $5 \%$ in public supply and $1 \%$ in self-supplied industries, while in some cases nearly $100 \%$ of the drinking water requirements are met from groundwater (Vryzas et al., 2012). A wide range of organic contaminants are present in groundwaters, which originate from many sources (industrial, municipal, agricultural, surface water exchange etc.). Despite the aforementioned significance of groundwaters for Greece, only limited information is published regarding the organic contamination of groundwaters.

Besides, a large number of coal-bearing geological basins exist in Greece, which are exploited by opencast mining and feed nearby lignite-fired power stations. The contribution of lignite to the total electric power output of the country exceeds $60 \%$ (Iordanidis et al., 2014). The pumped groundwater is used either for irrigation or for the drainage of the open-pit lignite mines. However, the organic pollutants originating from aquifers within lignite deposits are accused for endemic diseases, such as Balkan Endemic Nephropathy (Orem et al., 1999, 2007). Thus, there is an additional interest and environmental concern for the organic contamination assessment of these groundwaters.

The aim of the present study is to identify potential toxic or environmentally relevant organic compounds present in the aquifers of this region and to investigate a possible link of the identified organic contaminants with the Pliocene Amynteo lignites, i.e. whether leaching of lignite seams transferred organic micro-pollutants in the groundwater. It should be noted that the publications regarding organic pollutants of groundwaters from Greece are scarce and there has not been a similar study related to organic contamination in the groundwaters of this area so far.

\section{Description of study area}

Most Greek lignite deposits are located in the Florina-Ptolemais-Kozani basin, a large intensively exploited area, in northern Greece. The elongated intermontaine Florina-Ptolemais-Kozani basin is a NNW-SSE trending graben, which extends over a distance of $250 \mathrm{~km}$ from Bitola, in the Former Yugoslavian Republic of Macedonia to Servia, southeast of Kozani, Greece. Within this basin, Pliocene lignite beds alternate with marls, clays and sands. There is a great variance in the thickness of the overburden, intermediate and floor rocks as well as in the thickness of lignite seams. The average thickness of the overburden is approximately $260 \mathrm{~m}$ and of the lignite beds approx. $20 \mathrm{~m}$ (Iordanidis et al., 2014).

The Amynteo hydrogeological basin has a total surface of $228 \mathrm{~km}^{2}$ and belongs to the aforementioned coal-bearing basin (Gudulas, 2012). Numerous wells are located in the area, some of them employed for the drainage of the Amynteo open-pit lignite mine. The pumped groundwater is mainly used for irrigation. 


\section{Materials and Methods}

Ten groundwater samples were collected from the study area (Figure 1) and were stored in glass bottles in the dark at a temperature of approximately $4^{\circ} \mathrm{C}$. The samples were transferred in a portable fridge to the Laboratories of the Institute of Geology and Geochemistry of Petroleum and Coal, RWTH University, Aachen, Germany. Prior to extraction, water samples were filtered through pre-cleaned filters $(0.45 \mu \mathrm{m}$ pore size $)$ in order to remove suspended particulate matter from the aqueous phase.

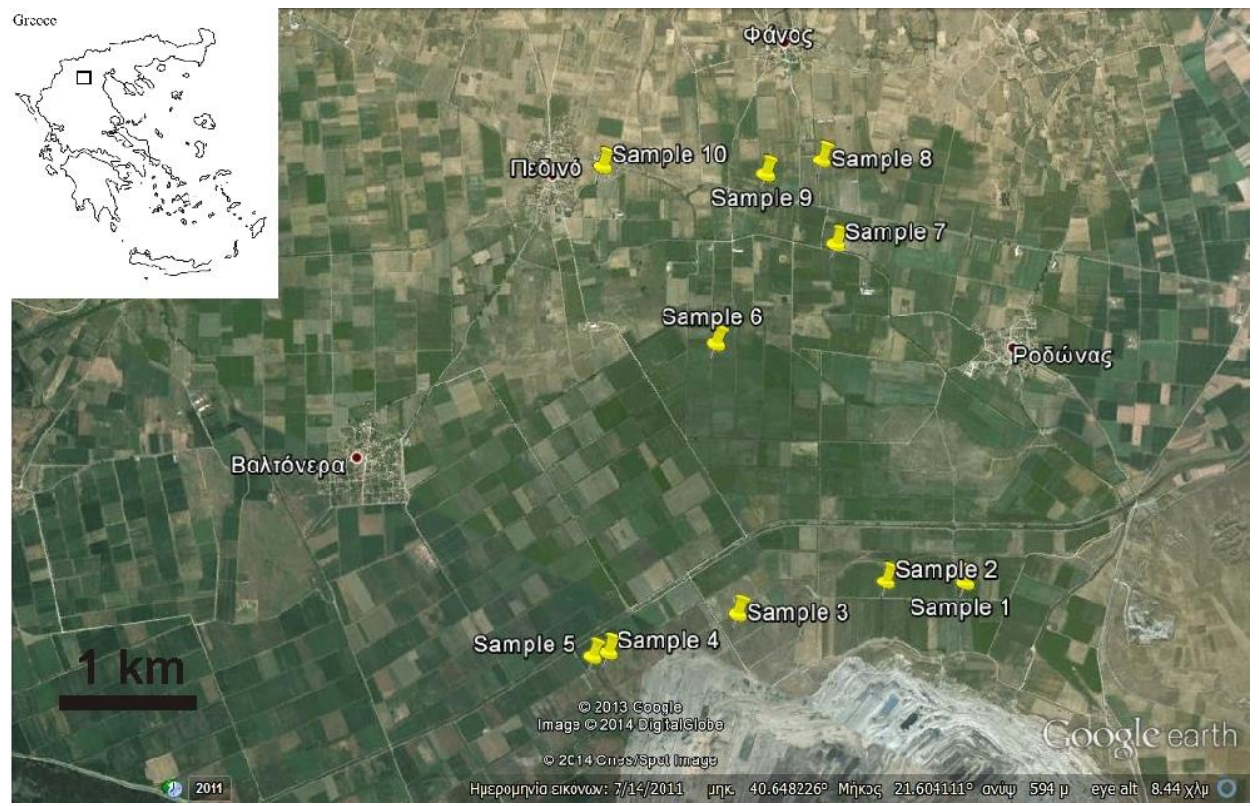

Figure 1 - Sampling sites of groundwaters from ten wells within Amynteo coal-bearing basin of northern Greece. The Amynteo lignite mine is clearly observed at the lower bottom of the image.

A sequential liquid-liquid extraction procedure was applied to approximately $1000 \mathrm{~mL}$ aliquots of the groundwater samples, dichloromethane (DCM) and dichloromethane after acidification to $\mathrm{pH} 2$ with hydrochloric acid. $50 \mathrm{~mL}$ of solvent were used for each extraction step. Thereafter, the organic layers were concentrated to approx. $1 \mathrm{~mL}$ by rotary evaporation at room temperature under reduced pressure and dried by filtration over $1 \mathrm{~g}$ of anhydrous granulated sodium sulphate. The analytical results of the non-polar and polar extracts are presented in this study. Prior to GC and GC/MS-analyses all extracts were further concentrated down to $50 \mu \mathrm{L}$ at room temperature under ambient pressure.

Gas chromatographic analyses were carried out on a Carlo Erba 6000 vega series 2 gas chromatograph, equipped with a ZB5 capillary column (30 mX0.25 mm IDX0.25 $\mu \mathrm{m}$ film). Flow velocity of the carrier gas (hydrogen) was $25 \mathrm{~cm} \mathrm{~s} 1$. The GC oven was programmed from 60 to 310 ${ }^{\circ} \mathrm{C}$ at a rate of $3{ }^{\circ} \mathrm{C} / \mathrm{min}$, after $3 \mathrm{~min}$ at the initial temperature. The injection was carried out on a split/splitless injector at $310{ }^{\circ} \mathrm{C}$, splitless time was $60 \mathrm{~s}$. Detection was conducted by a flame ionization detector (FID). GC/MS analyses were carried out with a Finnigan Trace MS mass spectrometer linked to a Carlo Erba HRGC 5160 gas chromatograph, employing the same conditions used for GC analysis.

\section{Results and Discussion}

The results of the GC and GC/MS analyses of the DCM extracts are presented in Figures 2, 3 and 4. It should be noted that in our study a non-target screening approach has been applied, hence only qualitative information are given. 


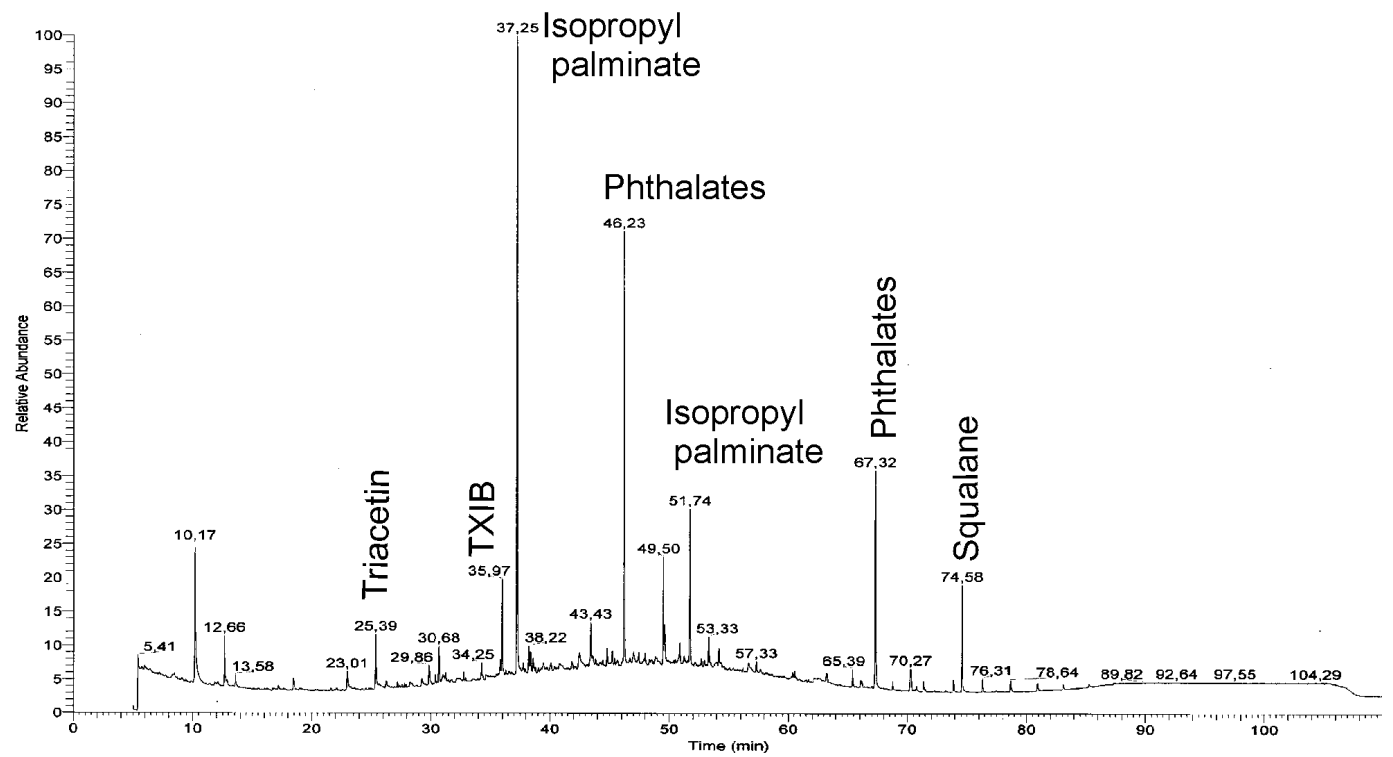

Figure 2 - Gas chromatogram of the DCM extract of the groundwater sample No 4. Specific organic compounds are assigned on the chromatogram (Triacetin, TXIB, Isopropyl palminate, Phthalates and Squalane).

Some of the identified organic compounds are shown in Figure 2, which is the gas chromatogram of the DCM extract of sample No 4. Very similar chromatograms were obtained by GC analyses of all other samples. The organic molecules presented in Fig. 2 are triacetin, TXIB, isopropyl palmitate, phthalates and squalane.

Under careful processing of the GC/MS results, some specific compounds were revealed. The assignment of the obtained mass spectra to specific molecules is shown in Figures 3 and 4 . In particular, the TXIB, tributyl phosphates and N, N-dibutyl formamide are shown in Figure 3 and methyl dihydrojasmonate, bumetrizole and nonyl phenols are encountered in Figure 4. A synopsis of the most significant compounds found in the DCM extracts of the samples of our study is shown in Table 1.

The identified organic compounds with a potential environmental relevance are: 2, 2, 4-trimethyl-1, 3-pentanediol diisobutyrate (TXIB), triacetine, isopropyl palminate, isopropyl myristate, tributyl-, triethyl- and trioctylphosphates, N, N-dibutyl formamide, methyl dihydrojasmonate, nonylphenols and bumetrizole.

TXIB is used as a plasticizer or the manufacture of PVC and vinyl plastics and its medium toxicity to fish was indicated in previous reports (Botalova et al., 2011). Triacetin detected in most of the studied samples. It is a known contaminant in propellant and industrial wastewaters as well as in surface water (Botalova et al., 2011). It is mainly used as a cellulosic plasticizer in the manufacture of cigarette filters, plasticizer for laminating resins, vinylidene polymers and copolymers. It is also used as a solvent and carrier in pharmaceutical preparations, in the compounding of perfumes and flavors, as well as an ingredient for printing inks and useful reagents in textile dyeing and the manufacture of photographic films. Therefore, it can be suggested to act as a potential indicator for these industrial processes. Triethyl phosphate was detected in several extracts of our samples. It is used as an industrial solvent, plasticizer for resins, plastics, gums, fire-retarding agent, defoamer and raw material for insecticides water (Botalova et al., 2011). Nonyl phenols, which are used as detergents and bumetrizole, which is used in cosmetics, were detected only in sample No 9 and are indeed frequently found in groundwaters (Lapworth et al., 2012). 
Table 1 - Abundance of organic pollutants in the groundwater samples of the present study.

\begin{tabular}{|c|c|c|c|c|c|c|c|c|c|c|}
\hline & $\begin{array}{l}\text { o } \\
\text { : } \\
\text { 信 }\end{array}$ & 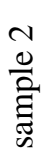 & 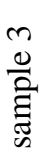 & 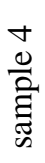 & 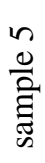 & 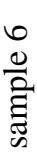 & $\begin{array}{l}\text { o } \\
\text { : } \\
\text { 离 }\end{array}$ & 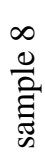 & 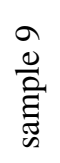 & 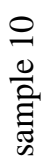 \\
\hline TXIB & + & + & + & + & + & + & + & + & + & \\
\hline Triacetin & & & + & + & & + & + & & + & + \\
\hline Isopropyl palminate & & + & + & + & + & + & + & & & + \\
\hline Isopropyl myristate & & & & & & + & & & & + \\
\hline $\begin{array}{l}\text { Tributyl-, triethyl- and } \\
\text { trioctyl- phosphate }\end{array}$ & & + & & & + & & & & + & + \\
\hline $\mathrm{N}, \mathrm{N}$-Dibutyl formamide & & & + & & & + & + & & & + \\
\hline Methyl dihydro jasmonate & & & & & & + & & & & + \\
\hline Nonylphenols & & & & & & & & & + & \\
\hline Bumetrizole & & & & & & & & & + & \\
\hline
\end{tabular}

Some detected compounds are also known as: Bumetrizole=Uvazol 236, Tinuvin 326, Benazol PBK4, Lowitite 26, Hydroxybutylmethylphenylchlorobenzotriazole; TXIB= Propanoic acid, 2, 2, 4trimethyl-1, 3-pentanediol diisobutyrate, Kodaflex

Likewise, methyl dihydrojasmonate, which is used for flavours and fragrances and isopropyl palminate and isopropyl myristate, which are used in cosmetics and personal care products were found in several samples of our study (Jurado et al., 2012). Phthalates are very common organic compounds (Schwarzbauer, 2006) with a versatile use (plastics etc.) and while some authors have attributed them to lignite extractable compounds (Orem et al., 1999), this could not be suggested in our study.

Compounds such as cycloalkanes/alkenes, steranic structures, mono aromatic and polyaromatic terpanes, polycyclic aromatic hydrocarbons, aromatic amines, and $\mathrm{N}-, \mathrm{S}-$, and O-containing heterocyclic compounds are often related to leachates from lignite deposits (McElmurry et al., 2004; Orem et al., 2007; Kapusta and Stanczyk, 2011; Iordanidis et al., 2012). Many of these compounds have attached oxygen-based functional groups (hydroxy-, phenol-, keto-, methoxy), and some of them contain heterocyclic nitrogen or amino groups, structural features that could make them nephrotoxic and carcinogenic. None of the aforementioned compounds were encountered in the DCM extracts of our samples.

In conclusion, all these organic micro-pollutants could have been derived either by anthropogenic emissions (plasticizers, industrial pollutants, pesticides etc.) or could be contamination from the pump and the borehole structure itself. Noteworthy, coal derived organic molecules have not been detected, such as anthracene, fluorene, pyrene, phenanthrene etc. (Kapusta and Stanczyk, 2011; Iordanidis et al., 2012). Hence, an influence of coal deposits to the groundwater quality is considered negligible. 

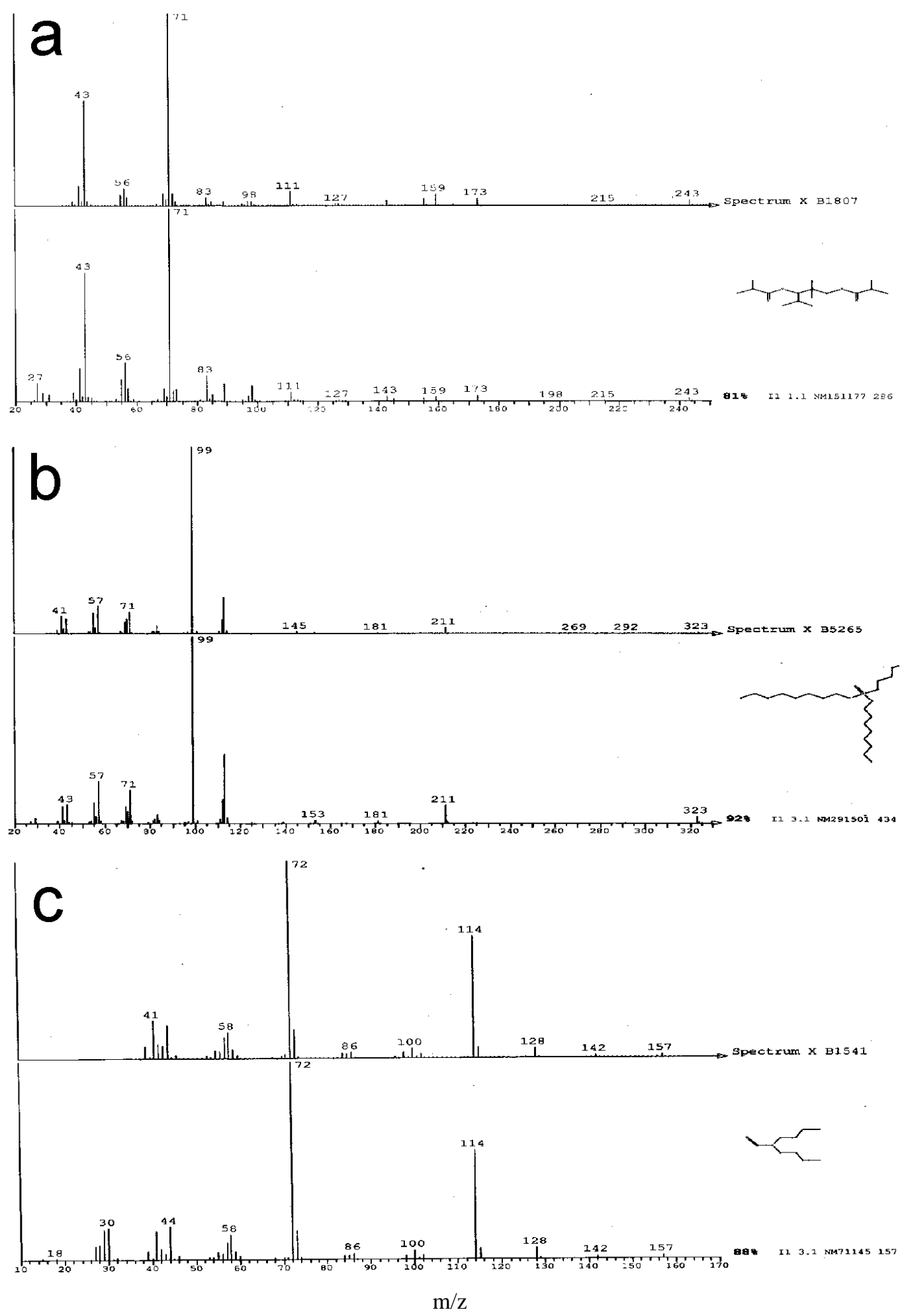

Figure 3 - Mass spectra assignment of specific organic molecules found in the GC-MS analysis of the DCM extracts of the groundwater samples: a) TXIB, b) Tributyl phosphate, c) N, N-dibutyl formamide. 

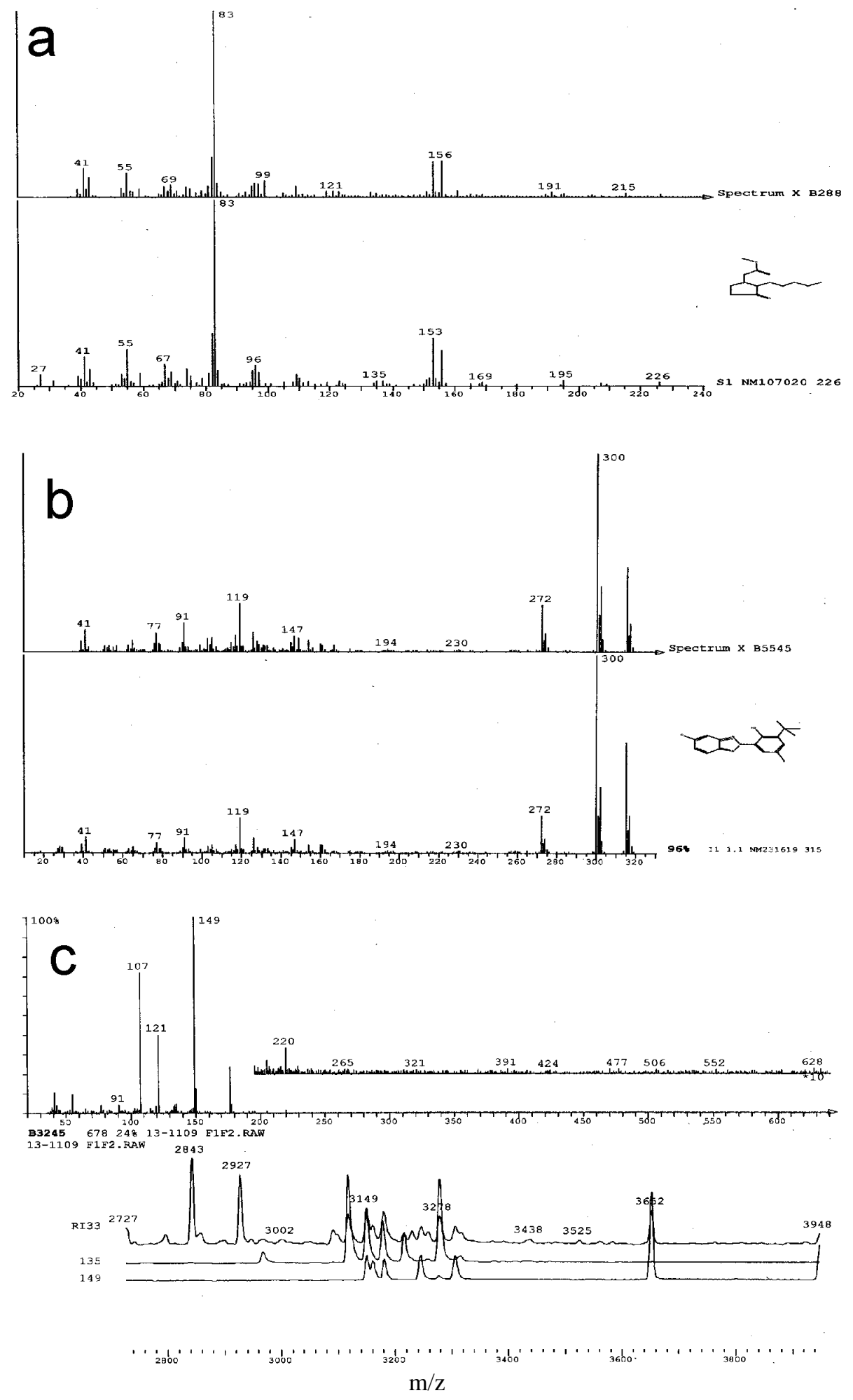

Figure 4 - Mass spectra assignment of specific organic molecules found in the GC-MS analysis of the DCM extracts of the groundwater samples: a) Methyl dihydrojasmonate, b) Bumetrizole, c) Nonyl phenols. 


\section{Acknowledgements}

The financial support of the German Academic Exchange Service (DAAD) through a short-term scholarship (A/13/04441) awarded to the first author for a research stay at RWTH, Aachen, Germany is gratefully acknowledged.

\section{References}

Botalova, O., Schwarzbauer, J. and Al Sandouk, N., 2011. Identification and chemical characterization of specific organic indicators in the effluents from chemical production sites, Water Research, 45, 3653-3664.

Gudulas, K., 2012. Investigation of the mechanisms of operation of lakes Cheimaditida and Zazari, located in the Amyntaio basin, of Florina County, from a hydrogeological and environmental point of view, PhD Thesis, School of Geology, Aristotle University of Thessaloniki, Greece.

Iordanidis, A., Georgakopoulos, A. and Kalaitzidis, S., 2014. Petrographic composition and palaeoenvironment of the Amynteo lignite deposit, northern Greece, Energy Sources, Part A Recovery, Utilization, and Environmental Effects, 36, 2715-2724.

Iordanidis, A., Schwarzbauer, J., Georgakopoulos, A. and Van Lagen, B., 2012. Organic geochemistry of Amynteo lignite deposit, northern Greece: a multi-analytical approach, Geochemistry International, 50(2), 159-178.

Jurado, A., Vàzquez-Suñé, E., Carrera, J., López de Alda, M., Estanislao Pujades, E. and Barceló, D., 2012. Emerging organic contaminants in groundwater in Spain: A review of sources, recent occurrence and fate in a European context, Science of the Total Environment, 440, 8294.

Kapusta, K. and Krzysztof, S., 2011. Pollution of water during underground coal gasification of hard coal and lignite, Fuel, 90, 1927-1934.

Lapworth, D.J., Baran, N., Stuart, M.E. and Ward, R.S., 2012. Emerging organic contaminants in groundwater: A review of sources, fate and occurrence, Environmental Pollution, 163, 287 303.

McElmurry, S.P. and Voice, T.C., 2004. Screening methodology for coal derived organic contaminants in water, International Journal of Environmental Analytical Chemistry, 84, 277-287.

Orem, W., Tatu, T., Pavlovic, N., Bunnell, J., Lerch, H., Paunescu, V., Ordodi, V., Flores, D., Corum, M. and Bates, A., 2007. Health Effects of Toxic Organic Substances from Coal: Toward "Panendemic" Nephropathy, AMBIO: A Journal of the Human Environment, 36(1), 98-102.

Orem, W.H., Feder, G.L. and Finkelman, R.B., 1999. A possible link between Balkan endemic nephropathy and the leaching of toxic organic compounds from Pliocene lignite by groundwater: preliminary investigation, International Journal of Coal Geology, 40, 237-252.

Schwarzbauer, J., 2006. Organic contaminants in riverine and groundwater systems - aspects of the anthropogenic contribution, Springer Verlag, Berlin/Heidelberg, 464 pp.

Vryzas, Z., Papadakis, E.N., Vassiliou, G. and Papadopoulou-Mourkidou, E., 2012. Occurrence of pesticides in trans boundary aquifers of North-eastern Greece, Science of the Total Environment, 441, 41-48. 